CIENCIA Y SOCIEDAD

Volumen XIV, Número 1

Enero - Marzo, 1989

\title{
LA PASANTLA RURAL COMO EXPERIENCIA DE SALUD COMUNITARIA
}

MIGUEL SUAZ0"

\section{Antecedentes}

En el año 1973 se fundó la Facultad de Medicina del INTEC, con la doble preocupación de:

1. Crear un médico dominicano para la República Dominicana.

2. Crear un programa que despertara la sensibilidad social y la vocación de servicio y que fuera respuesta a la realidad socio-económica del país.

En este contexto se ubica el diseño de una pasantía médica rural a mitad de la carrera, con los expresos objetivos de ser una experiencia curricular que propicie una mejor comprensión de la realidad nacional, contribuyendo a un compromiso solidario del estudiante con su pueblo.

La plataforma filosófica del INTEC encuadra a las pasantías cuando se define como:

a. Pertinencia social: dirigido a la concientización y búsqueda de respuestas a la realidad nacional.

Coordinador Pasantía Rural, Facultad de Medicina INTEC. Director de Investigaciones de INSAPEC. 
b. Perspectiva interdisciplinaria: o sea, el enfrentamiento al planteo de que la realidad es multifactorial y desborda los límites de una profesión para sus soluciones.

c. La Formación Continua: es decir, la necesidad de estar abiertos al conocimiento que nos brinda el contacto con la realidad.

d. La Vinculación Universidad-Trabajo: Significa, la necesidad que existe de que la Universidad esté vinculada a la sociedad no como campo de experimentación, sino como fuente de apoyo y alternativas.

e. Compromiso social o la manera de desarrollar en el estudiante una voluntad de compromiso.

f. Formación Integral: la cual la aporta el conocimiento dinámico de la teoría y la práctica, donde "las técnicas más eficientes se sustenten en un espíritu crítico muy desarrollado y una sensibilidad profunda en torno a los mejores valores humanos" (Reglamento Académico INTEC, Edición 1988, pp.45, Santo Domingo).

g. Por áltimo, la Retribución Social, donde el estudiante reconoce su deuda social e inicia la retribución en servicios y promoción a la sociedad.

La Pasantía Médica Rural queda pues definida como una proyección a la comunidad, en la que los procesos de aprendizaje se realizan a través de actividades que aunan a la docencia y la investigación, aprendizaje y trabajo, conocimiento de la realidad social dominicana y servicio a la comunidad (Reglamento Pasantía Rural 1985, pp. 7, Santo Domingo).

\section{Descripción}

Este modelo académico corresponde al 13-14 trimestre de la carrera de Medicina y tiene una duración de 2 trimestres académicos (22 semanas), donde los estudiantes viven en la comunidad en casas alquiladas, en grupos de 2 a 4 personas, de lunes a viernes, regresando a las aulas universitarias viernes en la tarde y sábado en la mañana a una experiencia dọcente denominada "Salud y Comunidad" y "Práctica Médica", para que junto a profesores e invitados se evalúe la experiencia semanal y se aporten nuevas líneas de apoyo de trabajo, que sería retomado el lunes siguiente, que es cuando se reintegran a su tarea.

En el campo participan durante la mañana en el área curativa (Clínicas Rurales-Sub-centros) según acuerdo SESPAS-INTEC, y el resto del día desarrollan un programa de Salud Comunitaria, donde se promueve la autogestión y la organización en torno a un amplio concepto del proceso salud-enfermedad.

Existe un componente investigación que desarrollan en cada semestre en base a prioridades encontradas, para luego contextualizar los programas de 
acción como verdaderas respuestas a las necesidades y como pautas para poder dar seguimiento a cada nueva pasantía a un mismo proyecto.

La supervisión de programas, actividades e inserción son realizadas por un profesor designado para dichas funciones, durante las visitas a la comunidad; por un coordinador que tiene bajo su responsabilidad garantizar el funcionamiento y la orientación de cada una de las partes y la docencia la cubre el equipo pasantía.

La Región de Salud en que incidimos es la I, cuya sede está en la ciudad de Baní y nuestra cobertura es en las comunidades de Baní y San Cristóbal.

El valor de la extensión institucional consiste en hacer presente al INTEC y su filosofía en los lugares señalados. La tendencia actual y coherente con la amplia concepción de salud, es incluir la participación de los estudiantes de Ingeniería, Psicología y Ecología, en las especificidades de sus áreas, en la modificación de los indicadores básicos de salud que son de su competencia.

En un contexto filosófico y un perfil del egresado definido como el que rezan los documentos del INTEC, hacer pasantía es hacer extensión del campo al sector social rural. Estar presente hoy sugiere hacer una labor no paternalista, donde el servicio y la organización -participación de la comunidad- esté acuñada por el grado de conciencia necesario para entender que la salud no es un regalo ni un premio, sino una reivindicación a levantar.

Las modificaciones sufridas por el país en los últimos años han impactado aún en el área rural, generando modelos extraños a nuestra realidad. Las remesas provenientes de los Estados Unidos, la transculturación de los ausentes en sus viajes a la isla, la drogadicción, el embarazo en la adolescencia, el SIDA, son ejemplos de esos cambios y nos han urgido a enfrentarlos en nuestros programas de acción, sugiriéndonos la dinamicidad de la tarea en el área de la salud comunitaria.

La sustitución de los implementos agrícolas por el motoconcho, la pobreza y marginación de la población, cuestionan la manera de hacer salud comunitaria sino es dirigida a elevar los niveles de conciencia del hombre, a vivir dignamente con el mínimo de recursos posibles, pero a conocer su derecho a disfrutar, aspirar y trabajar por tener el máximo de ellos.

\section{Sustrato Teórico}

La Pasantía Rural del INTEC está amparada en la concepción de salud que la plantea como el binomio salud-enfermedad, donde ambos polos interactúan, caracterizando la calidad de la vida de la colectividad y donde la comunidad interviene recuperando su derecho a no enfermar, en cuanto reivindicación social. 
Así se concretiza la intención de hacer salud comunitaria, descartando las visiones que la sindicaron como "policía médica", como legitimador del status, o como la actividad paternalista de grupos que asisten y proveen a la comunidad a través de obras de caridad. Tampoco se propugna por modelos, donde baste la presencia de un médico en la comunidad o donde los esquemas biologicistas exclusivizan la dimensión curativa de la medicina.

El derecho a no enfermar y a tener cubiertas las necesidades vitales es el objetivo que promueve la salud comunitaria, sin caer en legitimaciones. Auspiciando la participación y la autogestión como mecanismos viables para que puedan reconocer e identificar:

a) Sus necesidades.

b) Los responsables de garantizar su cobertura.

c) La potencialidad interna que tiene la autogestión para construir y demandar salud.

En ocasiones la comunidad, los estudiantes o los profesores no entienden qué hacen médicos bregando con agua potable, letrinas o microempresas. El objetivo académico es romper la absolutización del modelo biologicista para reconocer la utopía de la salud en la educación, vivienda, alimentación, ingresos, saneamiento, etc.

Una doble vía se materializa al involucrarnos durante 12 años en Pasantía Rural: 1. La que va en el sentido académico de formar un médico de mentalidad amplia, con una visión que desborde el aspecto curativo y el ámbito del consultorio, para entender al hombre en su dimensión humana y contextual; 2 . la que promueve en la comunidad el sentimiento necesario de obtener mejores condiciones de vida en todas las facetas que le son inherentes y resumirlas en una reivindicación a la que tiene que aspirar demandar y trabajar para conquistar.

Las esperanzas de vida al nacer han sido proyectadas para el período 19851990 en 65.9 años en ambos sexos. Las expectativas de vida y sus concretizaciones reales, lo mismo que las posibilidades de no enfermar, no son más que planteos estadísticos que se alejan de la realidad. En 1986 cerca de $1,771,304$ personas aparecieron por debajo de la línea de pobreza, debido a sus condiciones materiales de vida. Los indicadores básicos de salud (agua, vivienda y saneamiento) ampliamente conocidos por todos son reveladores de la conformación de condiciones inadecuadas para el desarrollo de una vida digna y saludable; ellos en sí establecen lo que se ha denominado el caracter social del proceso salud-enfermedad y la manera en que aún dentro de una misma sociedad se distribuye la enfermedad.

Ese entorno es más que justificación para entender por qué se debe intervenir en las condiciones sociales para aproximarse a la salud. La salud co- 
munitaria despierta en la población la conciencia del derecho a no enfermar y la necesidad de transformar las condiciones inhumanas de vida por otras más justas. El enfrentamiento entre un modelo biologicista unicausal genera los roces conocidos. El enfoque clínico y biologico es sumamente importante y válido en el curriculum siempre y cuando no se absolutice o antagonice con el comunitario y lo social tienen que servir para entender la complejidad del drama humano y para darle respuesta, no hacemos nada con sólo conocer a los microbios, sus ciclos y su agresividad, si no enseñamos a controlarlos y prevenirlos.

La Pasantía Rural intenta sintetizar ambos enfoques para dar una visión global al estudiante y formarlos de una manera crítica y conciente de su entorno social. Es a la comunidad a quien le corresponde poner el conocimiento científico a funcionar para interpretar la enfermedad en la cotidianidad del hombre del campo y devolverle sugerencias de acción que éste ejecute.

No estamos creando médicos artesanos, estamos gestando un modelo en que la retribución social de que hablan los reglamentos académicos del INTEC, consista en devolver el conocimiento científico para que la propia población levante sus brazos para transformar su realidad y construya la salud.

El binomio salud-enfermedad habla por sí solo de un proceso y no de una situación dada y estática. El concepto de enfermedad ha recorrido la historia de la humanidad tomando diversas connotaciones, desde comprenderse como un evento sobrenatural con sus implicaciones mágico-religiosas, el curar o atender al enfermo como una forma de garantizar la salvación del alma, hasta los hospitales cristianos como lugar de hacer la caridad. Es en la modalidad renacentista donde el servicio surge como un deber de asistir al necesitado; aquí la ciencia sustituyó a la religión en un franco proceso de secularización y es luego su absolutización y su diversificación entre lo privado y lo público en el hospital, lo que hace que el conocimiento médico se escinda y que se genere una distribución desigual de la enfermedad en la sociedad.

Este recorrido nos explica cómo la salud y la enfermedad son polos antagónicos de un mismo bloque. La enfermedad es una consecuencia de cómo las variables sociales impactan en la vida y en su calidad.

La Pasantía Rural entiende la necesidad de explorar esa realidad, para propiciar una autogestión crítica que permita desbordar el concepto clásico de salud curativa en el estudiante y la dimensión pasiva del hombre del campo que lo sindica como "paciente" también de sus propias limitaciones vitales.

\section{BIBLIOGRAFIA}

INTEC. Reglamentos Académicos. Santo Domingo, 1988. 
UNICEF-INTEC. Debate Nacional sobre la Situación de Niñez y la Mujer Dominicana. Santo Domingo, agosto-octubre, 1987.

Secretariado Técnico de la Presidencia. Oficina Nacional de Planificación. Fondo de las Naciones Unidas para la Infancia. Indicadores Básicos. Santo Domingo, 1986.

Medina, Jacqueline y Castillo, Angel. Anteproyecto Reglamento de Pasantía Rural. Santo Domingo, 1985.

Vasco Uribe, Alberto. "Sociología Médica". Serie Salud y Sociedad SESPAS. Santo Domingo, 1981.

Coe, Foucault, Weistens. "Salud, Hospital y Comunidad". Serie Salud y Comunidad. SESPAS. Santo Domingo, 1980.

Terris, Milton. La Revolución Epidemiológica y la Medicina Social. Siglo XXI, 2da. edición en español. Colombia, 1982.

Suazo, Miguel. Medicina Popular. Asociación Médica Dominicana. Santo Domingo, 1983. 